\title{
Synthesis, Crystal Structure, and DFT Study of Ethyl 1-(2-(Hydroxyimino)-2-phenylethyl)-3-phenyl-1H- pyrazole-5-carboxylate
}

\author{
Jin-Hui Zhou, ${ }^{1,2}$ Liang-Wen Zheng, ${ }^{2}$ Mao-Cai Yan, ${ }^{1}$ Mao-Jian Shi, ${ }^{1}$ \\ Jing Liu, ${ }^{1}$ and Guo-Qiang Shangguan ${ }^{1}$ \\ ${ }^{1}$ College of Pharmacy, Jining Medical University, Rizhao 276826, China \\ ${ }^{2}$ School of Chemistry and Chemical Engineering, University of Shandong, Jinan 250100, China \\ Correspondence should be addressed to Guo-Qiang Shangguan; gqshangguan@mail.jnmc.edu.cn
}

Received 6 July 2017; Revised 7 August 2017; Accepted 30 August 2017; Published 18 October 2017

Academic Editor: Josefina Pons

Copyright (C) 2017 Jin-Hui Zhou et al. This is an open access article distributed under the Creative Commons Attribution License, which permits unrestricted use, distribution, and reproduction in any medium, provided the original work is properly cited.

\begin{abstract}
The crystal structure of ethyl 1-(2-(hydroxyimino)-2-phenylethyl)-3-phenyl-1H-pyrazole-5-carboxylate has been determined by Xray single crystal diffraction. The crystal of the title compound is the monoclinic space group $P 2 / c$ with unit cell parameters of $a=8.634(2) \AA, b=9.616(2) \AA, c=22.190(3) \AA, \beta=99.265(2)^{\circ}, V=1818.3(4) \AA^{3}$, and $Z=4$. The dihedral angles formed by the planes of the central pyrazole ring and the adjacent benzene rings are $73.60(7)^{\circ}$ and $3.55(7)^{\circ}$, respectively. The combination of the weak intermolecular $\mathrm{C}-\mathrm{H} \cdots \mathrm{O}$ and $\mathrm{N}-\mathrm{H} \cdots \mathrm{O}$ hydrogen-bonding interactions stabilizes the crystal packing. The geometries of its $\mathrm{Z}$ and $\mathrm{E}$ isomers and the corresponding transition state (TS), as well as the dimer of its Z isomer, are optimized using the B3LYP hybrid functional coupled with def-TZVP triple-zeta polarized basis set. The bond angles and bond lengths of the optimized structure of $\mathrm{Z}$ dimer are very consistent with those of its single crystal parameters. Double-hybrid functional PWPB95-D3 in combination with very highly accurate basis set def2-QZVP is employed to evaluate accurate energy of each isomer and TS. The calculated equilibrium constant between $\mathrm{Z}$ and $\mathrm{E}$ isomers corresponds to the $[\mathrm{Z}] /[\mathrm{E}]$ ratio of 4.29. Mulliken atomic charges and electrostatic potential (ESP) on molecular van der Waals (vdW) surface are calculated in order to study and predict the intermolecular interactions. The molecular total energies and frontier orbital analysis are also discussed.
\end{abstract}

\section{Introduction}

Pyrazole oximes are one class of heterocyclic compounds which play a key role in the field of chemistry and pharmacology. It has been found that they exhibit various biological activities that are often related to low toxicity and increase a great amount of beneficial influences on human health. Therefore, they have attracted wide interest for decades owing to their diverse biological properties such as insecticidal [1], acaricidal [2], antitumor [3-5], fungicidal [6], antiviral [7, 8], antibacterial [9-11], COX inhibitory [12], and fluorescent [13, 14] properties.

In our paper, the structure of ethyl 1-(2-(hydroxyimino)2-phenylethyl)-3-phenyl-1H-pyrazole-5-carboxylate is determined by single crystal X-ray diffraction $[15,16]$. Its configuration of oxime bond and intermolecular interactions is confirmed. We have conducted density functional theory (DFT) calculations to prove that selected hybrid functionals and basis sets are particularly suitable for the calculations of the structural parameters, intermolecular hydrogen bonds, and equilibrium constant between $\mathrm{Z}$ and $\mathrm{E}$ isomers for oximes. Besides, this work provides a possibility to predict these parameters when a certain compound lacks its single crystal. Based on the reliable structure model, the DFT calculations are applied to investigate the optimized structural parameters, which is contrasted with the experimental $\mathrm{X}$ ray diffraction structure. The geometries of $\mathrm{Z}$ and $\mathrm{E}$ isomers and the corresponding transition state (TS), as well as the dimer of its $\mathrm{Z}$ isomer, are optimized using B3LYP hybrid functional coupled with def-TZVP triple-zeta polarized basis set. The bond angles and bond lengths of optimized structure 


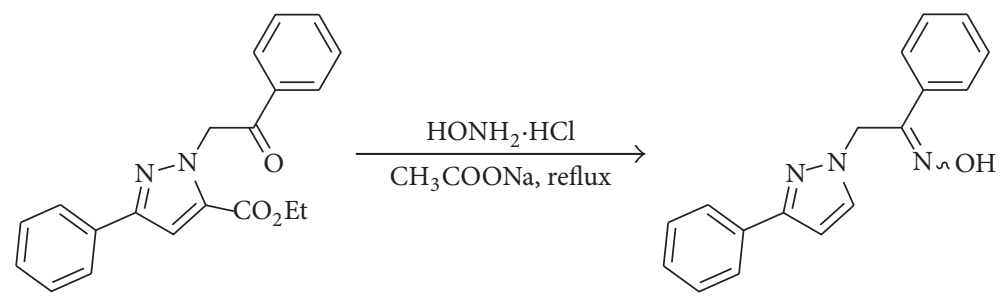

Scheme 1: Synthesis of ethyl 1-(2-(hydroxyimino)-2-phenylethyl)-3-phenyl-1H-pyrazole-5-carboxylate.

of $\mathrm{Z}$ dimer are very consistent with those of its single crystal parameters. Double-hybrid functional PWPB95-D3 in combination with very highly accurate basis set def2QZVP is employed to evaluate the accurate energy of each isomer and TS. The calculated equilibrium constant between $\mathrm{Z}$ and $\mathrm{E}$ isomers is calculated to be 4.29 ([Z]/[E]), which is close to the value estimated according to the experimental NMR spectra. The single crystal structure is $\mathrm{Z}$ configuration. Mulliken atomic charges and electrostatic potential (ESP) on molecular van der Waals (vdW) surface are calculated to study and predict intermolecular interactions. It is expected that the intermolecular hydrogen bonds must exist in title compound's molecular crystal. Indeed, the actual crystal structure nicely supports this point. In addition, the frontier orbital analysis and molecular total energies are discussed.

\section{Experimental}

2.1. Materials and Instrumentation. Chemical shifts of ${ }^{13} \mathrm{C}$ NMR and ${ }^{1} \mathrm{H}$ NMR spectra are recorded in ppm and NMR spectra are reported on a Bruker AVANCE $400 \mathrm{MHz}$ spectrometer (Bruker, Billerica, MA, USA) with the application of solvent shifts as internal criterion for ${ }^{13} \mathrm{C}$ and ${ }^{1} \mathrm{H}\left(\mathrm{CDCl}_{3}\right.$ : $\left.{ }^{13} \mathrm{C} d=77.0,{ }^{1} \mathrm{H} d=7.26\right)$. MS spectra are determined by LTQ Orbitrap Hybrid Mass Spectrometer (Thermo Fisher Scientific, Waltham, MA, USA). X-ray single crystal experiments are performed on a Bruker SMART CCD single crystal diffractometer (Bruker, Billerica, MA, USA).

2.2. Preparation of Title Compound. Synthesis of this compound (Scheme 1) refers to a previous literature [3]. Ethyl 1-(2-oxo-2-phenylethyl)-3-phenyl-1H-pyrazole-5-carboxylate (349.38 $\mathrm{mg}, 1.0 \mathrm{mmol}$ ) and hydroxylamine hydrochloride (347.45 mg, $5.0 \mathrm{mmol})$ in EtOH (40 ml) are added to a $100 \mathrm{ml}$ flask with a magnetic stirrer. The flask is stirred and heated slowly. After reflux for about $1 \mathrm{~h}$, sodium acetate anhydrous ( $410.15 \mathrm{mg}, 5.0 \mathrm{mmol}$ ) is added to the flask, which maintains continuous reflux for $1.5-4 \mathrm{~h}$. The solvent is removed; the resulting residue is partitioned with water and ethyl acetate layers afterwards. Brine and water are used to wash the organic layer successively, and then it is dried over $\mathrm{MgSO}_{4}$, evaporating under reduced pressure to give a residue. Recrystallization from absolute ethanol or silica gel column chromatography is used to purify the residue. The obtained target compound is a white solid. Single crystal is collected from the solution, which is obtained after the evaporation of solvent at low temperature for days.
TABLE 1: Crystal data of title compound.

\begin{tabular}{|c|c|}
\hline CCDC number & 1060837 \\
\hline Empirical formula & $\mathrm{C}_{20} \mathrm{H}_{19} \mathrm{~N}_{3} \mathrm{O}_{3}$ \\
\hline Formula weight & 349.38 \\
\hline Crystal system, space group & Monoclinic, $P 2 / c$ \\
\hline Temperature (K) & 293.15 \\
\hline$a, b, c(\AA)$ & $\begin{array}{c}8.634(2), 9.616(2) \\
22.190(3)\end{array}$ \\
\hline$V\left(\AA^{3}\right)$ & $1818.3(4)$ \\
\hline$\beta\left(^{\circ}\right)$ & $99.265(2)$ \\
\hline$Z$ & 4 \\
\hline Radiation type & $\mathrm{MoK} \backslash \mathrm{a}$ \\
\hline$\mu\left(\mathrm{mm}^{-1}\right)$ & 0.088 \\
\hline Crystal size (mm) & $0.14 \times 0.19 \times 0.23$ \\
\hline \multicolumn{2}{|l|}{ Data collection } \\
\hline Diffractometer & $\begin{array}{l}\text { Bruker SMART CCD } \\
\text { area-detector } \\
\text { diffractometer }\end{array}$ \\
\hline Absorption correction & $\begin{array}{c}\text { Multiscan (SADABS } \\
\text { in SAINT; Bruker, } \\
\text { 2002) }\end{array}$ \\
\hline$T \min , T \max$ & $0.97,0.99$ \\
\hline $\begin{array}{l}\text { Number of measured, } \\
\text { independent, and observed } \\
{[I>2 \sigma(I)] \text { reflections }}\end{array}$ & $15059,4196,2690$ \\
\hline$R_{\text {int }}$ & 0.0307 \\
\hline $\begin{array}{l}\text { Refinement } R\left[F^{2}>2 \sigma\left(F^{2}\right)\right] \\
w R\left(F^{2}\right), S\end{array}$ & $0.0573,0.1751$ \\
\hline Number of reflections & 4196 \\
\hline Number of parameters & 239 \\
\hline H-Atom treatment & Mixed \\
\hline$\Delta \rho_{\max }, \Delta \rho_{\min }\left(e \AA^{-3}\right)$ & $0.71,-0.26$ \\
\hline
\end{tabular}

2.3. Crystal Structure Determination. Crystals suitable for diffraction experiment are collected from the solutions. In addition to the data collection, Table 1 also summarizes the structural refinement details. The structure is solved and then refined using the OLEX2 program suite [17] that is equipped with SHELXS and SHELXL program [18]. All nonhydrogen atoms are placed from Fourier map directly by SHELXS and refined anisotropically. Hydrogen atoms on all nonhydrogen atoms are put in calculated positions, and their displacement parameters and coordinates are forced to depend on the 


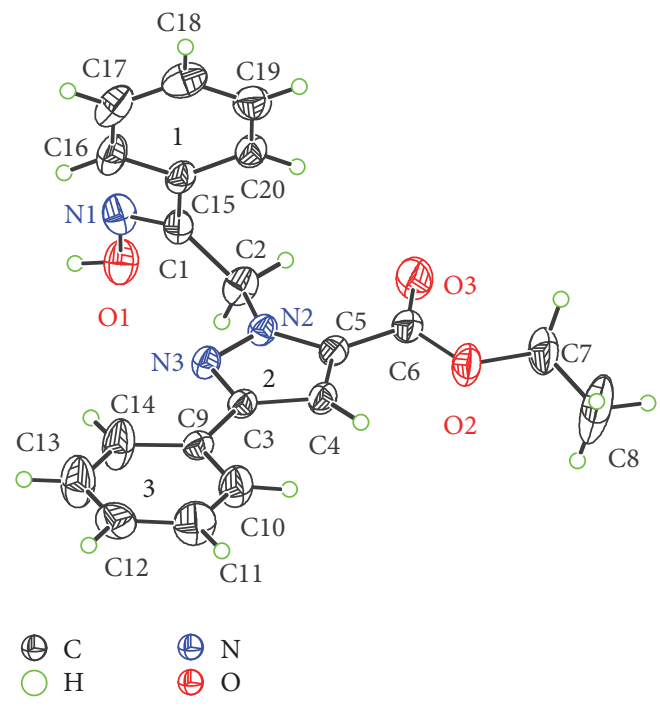

FIgURE 1: The asymmetrical unit of title compound. Color codes: C (gray), O (red), N (blue), and $\mathrm{H}$ (green). Displacement ellipsoids are drawn at the $30 \%$ probability level.

carrier atoms. The CIF file could be downloaded from http://www.ccdc.cam.ac.uk.

2.4. Computational Details. The geometries of $\mathrm{Z}$ and $\mathrm{E}$ isomers as well as the corresponding transition state (TS) are optimized using B3LYP hybrid functional [19] coupled with def-TZVP triple-zeta polarized basis set [20] within Gaussian 03 package [21]. Then the optimized structures are subjected to frequency analysis at the same level to obtain thermodynamic correction values. Vibrational frequency analysis shows that the optimized structures correspond to the lowest points on the potential energy surfaces without virtual frequencies, which means that the optimized structure is stable. Double-hybrid functional PWPB95-D3 [22] in combination with very highly accurate basis set def2-QZVP [23] is employed to evaluate the accurate energy of each isomer and TS. In this process, the resolution of identity (RI) technique [24] is applied to accelerate electron integral calculations. The molecular electrostatic potential at the B3LYP/TZVP level is analyzed by Multiwfn 3.3.7 software [25] and then plotted using VMD 1.9.1 program [26]. The composition (\%) of atomic orbitals in molecular frontier orbitals is analyzed by Multiwfn software.

\section{Results and Discussion}

3.1. Crystal Structure. As shown in Figure 1, the asymmetrical unit contains an independent molecule of title compound. The detailed analysis of the molecule shows that all the bond lengths and bond angles are within the normal ranges. The molecule is nonplanar. The dihedral angles that are made by the plane of the central pyrazole ring (ring-2) and its adjacent benzene rings (ring-1 and ring- 3 ) are $73.60(7)^{\circ}$ and $3.55(7)^{\circ}$, respectively. The bond lengths of $\mathrm{N} 1-\mathrm{Cl}$ and $\mathrm{N1}-\mathrm{O} 1$ are $1.298(3) \AA$ and $1.382(3) \AA$, respectively, which confirms that the bond between $\mathrm{N} 1$ and $\mathrm{O} 1$ atoms is oxime bond. The
TABLE 2: Hydrogen-bond and C-H $\cdots \pi$ geometry $\left(\AA\right.$ and $\left.^{\circ}\right)$ of title compound ${ }^{\mathrm{a}}$.

\begin{tabular}{lcccc}
\hline $\mathrm{D}-\mathrm{H} \cdots \mathrm{A}$ & $\mathrm{D}-\mathrm{H}$ & $\mathrm{H} \cdots \mathrm{A}$ & $\mathrm{D} \cdots \mathrm{A}$ & $\mathrm{D}-\mathrm{H} \cdots \mathrm{A}$ \\
\hline $\mathrm{O}_{1}-\mathrm{H} 1 \cdots \mathrm{N} 3^{\mathrm{i}}$ & $0.849(10)$ & $1.976(10)$ & $2.825(2)$ & $177(4)$ \\
$\mathrm{C} 14-\mathrm{H} 14 \cdots \mathrm{O}^{\mathrm{i}}$ & 0.93 & 2.58 & $3.471(3)$ & 162.1 \\
$\mathrm{C} 17-\mathrm{H} 17 \cdots \mathrm{O}^{\text {ii }}$ & 0.93 & 2.71 & $3.517(3)$ & 146.3 \\
$\mathrm{C} 19-\mathrm{H} 19 \cdots \mathrm{O} 3^{\text {iii }}$ & 0.93 & 2.61 & $3.287(3)$ & 129.7 \\
$\mathrm{C} 11-\mathrm{H} 11 \cdots \mathrm{Cgl}^{\text {iv }}$ & 0.93 & 2.95 & $3.733(6)$ & 143 \\
$\mathrm{Cg} 3 \cdots \mathrm{Cg}^{\text {iv }}$ & - & - & $3.794(3)$ & $0.0(3)$ \\
$\mathrm{Cg}^{\mathrm{i}} \cdots \mathrm{Cg}^{\mathrm{v}}$ & - & - & $4.044(2)$ & $3.38(9)$ \\
\hline
\end{tabular}

${ }^{a}$ Symmetry code: (i) $1-x, 2-y, 1-z$; (ii) $x-1, y, z$; (iii) $1-x, y, 1.5-z$;

(iv) $-x, 1-y, 1-z$; (v) $1-x, 1-y, 1-z$. Cg is the centroid of the ring.

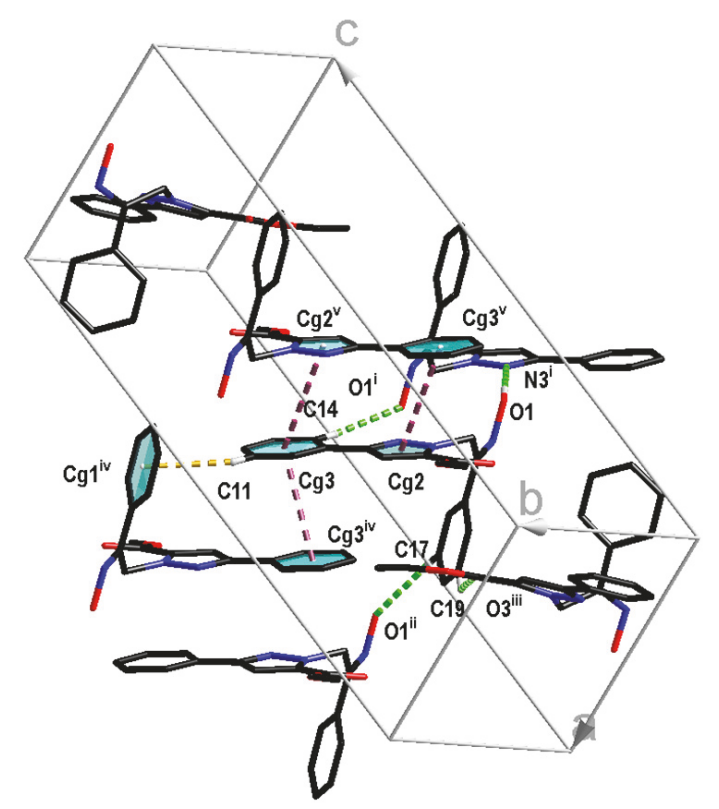

FIGURE 2: The intermolecular hydrogen-bonding interactions (green-dashed lines), $\pi-\pi$ stacking interactions (carmine-dashed lines), and $\mathrm{C}-\mathrm{H} \cdots \pi$ interactions (orange-dashed lines) in title compound. Uncorrelated hydrogen atoms are omitted for clarity. H-Atoms on C11, C14, C17, and C19 are H11, H14, H17, and H19, respectively. Color codes: $\mathrm{C}$ (black), $\mathrm{O}$ (red), $\mathrm{N}$ (blue), and $\mathrm{H}$ (white).

torsion angle of O1-N1-C1-C2 is $0.1(3)^{\circ}$, which reveals that the configuration of the double bond is $\mathrm{Z}$.

The supramolecular structure of title compound is formed by various weak interactions, including hydrogenbonding interactions, aromatic $\pi-\pi$ stacking interactions, and $\mathrm{C}-\mathrm{H} \cdots \pi$ interactions. As shown in Figure 2, a dimer is formed through intermolecular hydrogen bond O1$\mathrm{H} 1 \cdots \mathrm{N} 3^{\mathrm{i}}$. The $3 \mathrm{D}$ supramolecular structure is obtained through the weak hydrogen bonds $\left(\mathrm{C} 14-\mathrm{H} 14 \cdots \mathrm{O}^{\mathrm{i}}, \mathrm{Cl}\right.$ $\left.\mathrm{H} 17 \cdots \mathrm{O} 1^{\mathrm{ii}}, \mathrm{C} 19-\mathrm{H} 19 \cdots \mathrm{O} 3^{\mathrm{iii}}\right)$. The structure expanded along an axis through $\mathrm{C} 17-\mathrm{H} 17 \cdots \mathrm{O} 1^{\text {ii }}$ as a $\mathrm{C}(7)$ motif. The hydrogen-bonding data are shown in Table 2. In addition to the hydrogen-bonding interactions, there are several aromatic $\pi-\pi$ stacking interactions. The aspectant $\pi-\pi$ stacking can be found between ring- 2 and ring- 3 at $(1-x, 1-y, 1-z)$ 
TABLE 3: Selected experimental and theoretical geometrical parameters of title compound.

\begin{tabular}{|c|c|c|c|c|}
\hline \multirow{2}{*}{ Bond type } & \multicolumn{2}{|c|}{ Calculated data } & \multirow{2}{*}{ Experimental data } & \multirow{2}{*}{ Atomic number } \\
\hline & Monomer & Dimer & & \\
\hline $\mathrm{O}-\mathrm{H}$ & 0.96366 & 0.82034 & $0.85(1)$ & $\mathrm{O}(1)-\mathrm{H}(1)$ \\
\hline $\mathrm{N}-\mathrm{O}$ & 1.40710 & 1.38079 & $1.382(3)$ & $\mathrm{N}(1)-\mathrm{O}(1)$ \\
\hline $\mathrm{C}=\mathrm{N}$ & 1.27849 & 1.29849 & $1.298(3)$ & $\mathrm{C}(1)-\mathrm{N}(1)$ \\
\hline $\mathrm{C}-\mathrm{C}$ & 1.51621 & 1.50113 & $1.502(3)$ & $C(1)-C(2)$ \\
\hline $\mathrm{C}-\mathrm{C}$ & 1.48329 & 1.47365 & $1.472(3)$ & $\mathrm{C}(1)-\mathrm{C}(15)$ \\
\hline $\mathrm{N}-\mathrm{N}$ & 1.33374 & 1.34626 & $1.347(2)$ & $\mathrm{N}(2)-\mathrm{N}(3)$ \\
\hline $\mathrm{C}=\mathrm{O}$ & 1.21574 & 1.19728 & $1.198(3)$ & $\mathrm{C}(6)-\mathrm{O}(3)$ \\
\hline $\mathrm{C}-\mathrm{O}$ & 1.34447 & 1.32638 & $1.326(3)$ & $\mathrm{C}(6)-\mathrm{O}(2)$ \\
\hline $\mathrm{C}-\mathrm{N}$ & 1.37160 & 1.35496 & $1.355(2)$ & $\mathrm{C}(5)-\mathrm{N}(2)$ \\
\hline $\mathrm{C}=\mathrm{N}$ & 1.34089 & 1.33854 & $1.338(2)$ & $\mathrm{C}(3)-\mathrm{N}(3)$ \\
\hline $\mathrm{C}-\mathrm{C}$ & 1.51153 & 1.48621 & $1.486(5)$ & $C(7)-C(8)$ \\
\hline $\mathrm{C}=\mathrm{C}$ & 1.38405 & 1.37172 & $1.371(3)$ & $\mathrm{C}(4)-\mathrm{C}(5)$ \\
\hline $\mathrm{C}=\mathrm{C}$ & 1.40663 & 1.39875 & $1.398(3)$ & $\mathrm{C}(3)-\mathrm{C}(4)$ \\
\hline $\mathrm{N}-\mathrm{O}-\mathrm{H}$ & 102.132 & 109.472 & $104(2)$ & $\mathrm{N}(1)-\mathrm{O}(1)-\mathrm{H}(1)$ \\
\hline $\mathrm{O}-\mathrm{N}=\mathrm{C}$ & 113.709 & 111.984 & $111.8(2)$ & $\mathrm{C}(1)-\mathrm{N}(1)-\mathrm{O}(1)$ \\
\hline $\mathrm{N}=\mathrm{C}-\mathrm{C}$ & 116.326 & 114.806 & $114.7(2)$ & $\mathrm{N}(1)-\mathrm{C}(1)-\mathrm{C}(15)$ \\
\hline C-C-C & 120.278 & 120.387 & $120.5(2)$ & $\mathrm{C}(16)-\mathrm{C}(15)-\mathrm{C}(1)$ \\
\hline $\mathrm{N}=\mathrm{C}-\mathrm{C}$ & 123.507 & 123.628 & $123.7(2)$ & $\mathrm{N}(1)-\mathrm{C}(1)-\mathrm{C}(2)$ \\
\hline $\mathrm{C}-\mathrm{C}-\mathrm{N}$ & 111.805 & 112.751 & $112.8(2)$ & $\mathrm{N}(2)-\mathrm{C}(2)-\mathrm{C}(1)$ \\
\hline C-N-N & 118.218 & 118.666 & $118.6(2)$ & $\mathrm{N}(3)-\mathrm{N}(2)-\mathrm{C}(2)$ \\
\hline $\mathrm{N}-\mathrm{C}-\mathrm{C}$ & 124.600 & 123.927 & $123.9(2)$ & $\mathrm{N}(2)-\mathrm{C}(5)-\mathrm{C}(6)$ \\
\hline $\mathrm{C}-\mathrm{C}-\mathrm{O}$ & 125.689 & 126.451 & $126.4(2)$ & $\mathrm{O}(3)-\mathrm{C}(6)-\mathrm{C}(5)$ \\
\hline $\mathrm{C}-\mathrm{C}-\mathrm{O}$ & 110.964 & 109.733 & $109.8(2)$ & $\mathrm{O}(2)-\mathrm{C}(6)-\mathrm{C}(5)$ \\
\hline $\mathrm{N}-\mathrm{C}-\mathrm{C}$ & 120.850 & 121.304 & $121.3(2)$ & $\mathrm{N}(3)-\mathrm{C}(3)-\mathrm{C}(9)$ \\
\hline
\end{tabular}

position and between ring- 1 and ring- 3 at $(-x, 1-y, 1-$ $z)$ position. The structure expanded along [110] direction through $\mathrm{O} 1-\mathrm{H} 1 \cdots \mathrm{N} 3^{\mathrm{i}}$ and $\mathrm{Cg} 3 \cdots \mathrm{Cg} 3^{\mathrm{iv}}$. The $\pi-\pi$ stacking interactions are characterized by a centroid to centroid distance of 3.794(3) $\AA$ with ring slippage of $1.102 \AA$ for the former and a centroid to centroid distance of 4.044(2) $\AA$ for the latter. The $\pi-\pi$ stacking data are presented in Table 2 .

3.2. Optimized Geometries. It should be mentioned that the optimized hydrogen bonds are $13 \%-17 \%$ longer than those in the corresponding crystal structure of $\mathrm{Z}$ isomer monomer. This phenomenon is common, as the position of the hydrogen atoms always cannot be measured correctly. The distances between nonhydrogen atoms are in consistency with the experimental values, whose deviation does not exceed $0.02 \AA$. The bond angles are also in consistency with the corresponding experimental values with a deviation smaller than $2^{\circ}$ (Table 3 ). The differences between some calculated and experimental dihedral angles are much large, which can be attributed to the different treated methods. The optimization is performed in vacuo, and the dihedral angles are quite flexible. However, in the crystal structures, all the bonds and bond angles would be restricted obviously. Figure 3 shows the plots of $\mathrm{Z}$ and $\mathrm{E}$ configurations of title compound. The positions of their hydroxyl groups are different, and other geometries remain almost unchanged except for the dihedral angles between benzene rings. The bond angles and bond lengths of optimized structure of $Z$ dimer are very consistent with those of the structural parameters of single crystal.

The selected experimental and theoretical geometrical parameters of monomer and dimer of $\mathrm{Z}$ isomer are shown in Table 3. Compared with the crystal structure values, the bond lengths $\mathrm{N}(1)-\mathrm{O}(1)$ and $\mathrm{O}(1)-\mathrm{H}(1)$ of $\mathrm{Z}$ isomer dimer have a deviation of about $0.02 \AA$; the band angle $\mathrm{N}(1)-\mathrm{O}(1)-\mathrm{H}(1)$ of $\mathrm{Z}$ isomer dimer has a deviation of about $5^{\circ}$. Except for the above deviations, the other bond lengths of title compound are almost the same. The causes of deviations may be ascribed to the intermolecular hydrogen bonding in crystal.

3.3. Isomers' Energies. The single-point energies of $\mathrm{Z}$ and $\mathrm{E}$ isomers are -1163.366685225933 Hartree and -1163.365234699443 Hartree at the high-accurate PWPB95D3/def2-QZVP level of theory, respectively. Therefore, the conformational energy of $\mathrm{E}$ isomer is $3.81 \mathrm{~kJ} / \mathrm{mol}$ higher than that of $\mathrm{Z}$ isomer. Based on the Gibbs energy correction by the above method, the Gibbs energy difference between $\mathrm{Z}$ and $\mathrm{E}$ isomers is $3.61 \mathrm{~kJ} / \mathrm{mol}$. Therefore, the equilibrium constant between $\mathrm{Z}$ and $\mathrm{E}$ isomers can be calculated by employing the following equation: $\Delta G=-R T \ln K$. At $298.15 \mathrm{~K}$, the equilibrium constant is calculated to be 0.2331 , which corresponds to the $[\mathrm{Z}] /[\mathrm{E}]$ ratio of 4.29 . It is close to the value of 3.7 that is estimated according to the experimental NMR spectra [3]. 


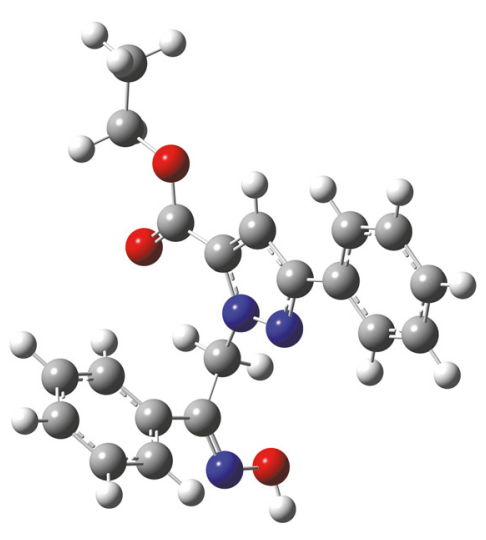

Z

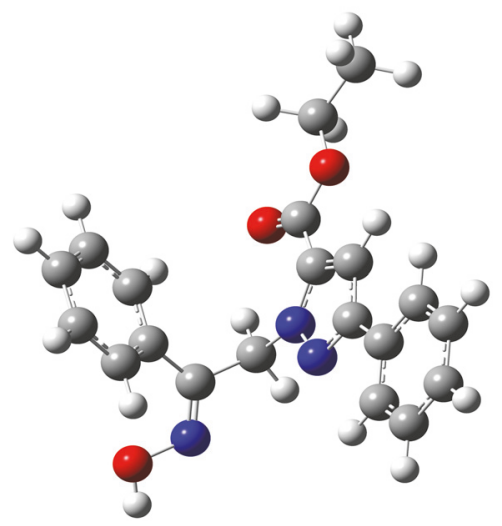

E

Figure 3: The plots of $\mathrm{Z}$ and $\mathrm{E}$ configurations of title compound.

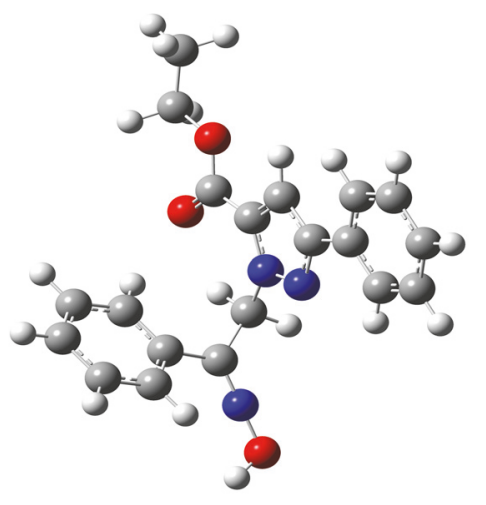

FIGURE 4: The plot of TS configuration of title compound.

3.4. Transition State. The transition state (TS) (Figure 4) of the Z-E tautomerism is located. Obviously, the hydroxyl C$\mathrm{N}-\mathrm{O}$ is almost in a straight line with a bond angle of $177.85^{\circ}$. The TS energy is $224.88 \mathrm{~kJ} / \mathrm{mol}$ and $228.69 \mathrm{~kJ} / \mathrm{mol}$ higher than that of $\mathrm{E}$ and $\mathrm{Z}$ isomers, respectively.

3.5. Frontier Orbital Energy Analysis and Molecular Total Energies. The frontier orbital energy levels and molecular total energies are demonstrated in Table 4, and their corresponding frontier orbital plots are shown in Figure 6, which are calculated at the B3LYP/def-TZVP level of theory. The most important orbitals in title compound are the frontier molecular orbitals, which are called LUMO and HOMO. The LUMO stands for an ability to get an electron, and HOMO expresses the ability to donate an electron [27] as an electron acceptor. Therefore, they are the most significant factors that influence the bioactivity, and the study on the frontier orbital energy can offer helpful information about the biological mechanism. The energy gap between HOMO and LUMO is 0.17039 Hartree, which indicates that this molecule is chemically inactive, as it cannot be easily excited by small energy. In Figure 6, HOMO is basically on phenyl diazine part of molecule, while LUMO is almost localized on the
TABLE 4: Total energy and frontier orbital energy ${ }^{\mathrm{a}}$.

\begin{tabular}{lc}
\hline & Energy \\
\hline$E_{\text {total }} /$ Hartree & -1163.83 \\
$E_{\mathrm{HOMO}-4} /$ Hartree & -0.26884 \\
$E_{\mathrm{HOMO}-3} /$ Hartree & -0.25915 \\
$E_{\mathrm{HOMO}-2} /$ Hartree & -0.25683 \\
$E_{\mathrm{HOMO}-1} /$ Hartree & -0.24092 \\
$E_{\mathrm{HOMO}} /$ Hartree & -0.22923 \\
$\Delta E^{\mathrm{b}}$ & 0.17039 \\
$E_{\mathrm{LUMO}} /$ Hartree & -0.05884 \\
$E_{\mathrm{LUMO}+1} /$ Hartree & -0.04354 \\
$E_{\mathrm{LUMO}+2} /$ Hartree & -0.03342 \\
$E_{\mathrm{LUMO}+3} /$ Hartree & -0.01384 \\
$E_{\mathrm{LUMO}+4} /$ Hartree & -0.01049 \\
\hline${ }^{\mathrm{a}} 1 \mathrm{Hartree}=4.35974417 \times 10^{-18} ; 1 \mathrm{~J}=27.2113845 \mathrm{eV} ;{ }^{\mathrm{b}} \Delta E=E_{\mathrm{LUMO}}-E_{\mathrm{HOMO}}$.
\end{tabular}

whole molecule except for the phenyl ring of phenyl diazine part. Therefore, the electrons transit from the phenyl diazine part to almost whole molecule. The HOMO-LUMO gaps of $\mathrm{Z}$ and $\mathrm{E}$ isomers are obtained at the B3LYP/def-TZVP level of theory, where their HOMO-LUMO gaps are $4.637 \mathrm{eV}$ and $4.665 \mathrm{eV}$, respectively.

Table 5 shows the composition (\%) of atomic orbitals in HOMO and LUMO orbitals, respectively, where the percentage over $0.5 \%$ is shown. Obviously, the atomic orbitals of N1, C2, N3, C11, C14, C25, C29, and C31 occupy the most composition (\%) of HOMO and N1, N3, O7, C10, C14, O16, C17, and C18 occupy almost the whole composition (\%) of LUMO. The atomic number in molecule is shown in Figure 5. The understanding of the composition (\%) of atomic orbitals in molecule would be helpful for the studies on the electronand/or charge-transfer character.

3.6. Mulliken Atomic Charges and Molecular Electrostatic Potential. The computed Mulliken atomic charges of all atoms of title compound are shown in Table 6. There are small charges in terms of all the nitrogen atoms. All the 
TABLE 5: The composition (\%) of atomic orbitals in HOMO or LUMO of molecule.

\begin{tabular}{lcc}
\hline Atom & HOMO percentage & LUMO percentage \\
\hline $\mathrm{N} 1$ & $7.00 \%$ & $13.94 \%$ \\
$\mathrm{~N} 3$ & $11.41 \%$ & $11.12 \%$ \\
$\mathrm{~N} 8$ & $0.88 \%$ & $0.75 \%$ \\
$\mathrm{C} 9$ & $0.52 \%$ & $0.96 \%$ \\
$\mathrm{C} 10$ & $2.26 \%$ & $11.37 \%$ \\
$\mathrm{C} 29$ & $8.81 \%$ & $0.92 \%$ \\
$\mathrm{C} 11$ & $11.02 \%$ & $0.66 \%$ \\
$\mathrm{C} 14$ & $8.30 \%$ & $12.51 \%$ \\
$\mathrm{O} 16$ & $0.61 \%$ & $13.50 \%$ \\
$\mathrm{H} 22$ & $0.88 \%$ & $1.07 \%$ \\
$\mathrm{C} 33$ & $3.25 \%$ & $0.76 \%$ \\
\hline
\end{tabular}

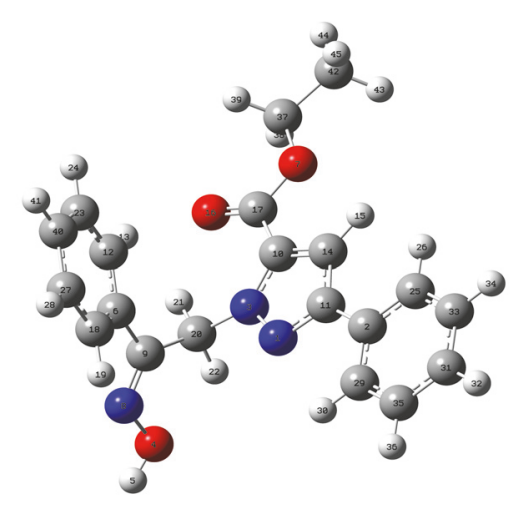

FIGURE 5: Optimized geometry of title compound and its atomic numbers.

oxygen atoms $(\mathrm{O} 4, \mathrm{O} 7$, and $\mathrm{O} 16)$ and some of carbon atoms (C2, C20, C23, and C42) have large negatively charged ones, which can have a facile interaction with the positively charged part of the receptor. The atom with the most negative charge is O16, followed by C42 and O4. Therefore, C42 is ready for electrophilic attack. All carbon atoms have negative charges except for the cases of $\mathrm{C17}$ and C11, which would be responsible for nucleophilic attack sites.

Electrostatic potential (ESP) on molecular van der Waals $(\mathrm{vdW})$ surface is important to study and predict the intermolecular interactions [28-30]. It is well known that intermolecular recognition and electrostatic dominated noncovalent interactions tend to occur in terms of electrostatically complementary manner. The investigation of ESP of title compound is supposed to be useful to understand its intermolecular interactions. The ESP mapped vdW surface coped with surface extrema of $Z$ isomer is shown in Figure 7(a).

From Figure 7(a), it can be seen that the global maximum of ESP on van der Waals surface is present in the orange sphere with $+44.3 \mathrm{kcal} / \mathrm{mol}$, which is the direct consequence of the significantly positively charged hydroxyl hydrogen. Such a high value of ESP indicates that this hydroxyl group must be able to behave as a strong $\mathrm{H}$-bond donor. In
TABLE 6: Mulliken atomic charges of title compound.

\begin{tabular}{|c|c|}
\hline Atom & Charge \\
\hline $\mathrm{N} 1$ & -0.061300 \\
\hline $\mathrm{C} 2$ & -0.147918 \\
\hline N3 & 0.057386 \\
\hline $\mathrm{O} 4$ & -0.302941 \\
\hline H5 & 0.288510 \\
\hline C6 & -0.002504 \\
\hline O7 & -0.186096 \\
\hline N8 & 0.013476 \\
\hline C9 & -0.072248 \\
\hline $\mathrm{C} 10$ & -0.047429 \\
\hline $\mathrm{C} 11$ & 0.016290 \\
\hline $\mathrm{C} 12$ & -0.111760 \\
\hline $\mathrm{C} 25$ & -0.096077 \\
\hline $\mathrm{H} 26$ & 0.106782 \\
\hline $\mathrm{C} 27$ & -0.093525 \\
\hline $\mathrm{H} 28$ & 0.109823 \\
\hline $\mathrm{C} 29$ & -0.138813 \\
\hline Н30 & 0.130015 \\
\hline C31 & -0.105148 \\
\hline H32 & 0.106597 \\
\hline $\mathrm{C} 33$ & -0.087616 \\
\hline H34 & 0.102026 \\
\hline C35 & -0.070456 \\
\hline H13 & 0.174212 \\
\hline $\mathrm{C} 14$ & -0.014417 \\
\hline H15 & 0.160320 \\
\hline $\mathrm{O} 16$ & -0.355410 \\
\hline $\mathrm{C} 17$ & 0.105030 \\
\hline $\mathrm{C} 18$ & -0.092596 \\
\hline H19 & 0.120824 \\
\hline $\mathrm{C} 20$ & -0.227730 \\
\hline $\mathrm{H} 21$ & 0.199381 \\
\hline $\mathrm{H} 22$ & 0.183246 \\
\hline $\mathrm{C} 23$ & -0.130862 \\
\hline $\mathrm{H} 24$ & 0.107364 \\
\hline C37 & -0.054152 \\
\hline H38 & 0.129783 \\
\hline H39 & 0.127008 \\
\hline $\mathrm{C} 40$ & -0.097878 \\
\hline H41 & 0.110371 \\
\hline $\mathrm{C} 42$ & -0.327594 \\
\hline $\mathrm{H} 43$ & 0.126005 \\
\hline H44 & 0.119205 \\
\hline H45 & 0.124974 \\
\hline H36 & 0.105841 \\
\hline
\end{tabular}

Figure $7(\mathrm{a})$, there are two notable regions where the color is deep blue, and both of them have the corresponding ESP minimum, which reflect the remarkable negative contribution to ESP due to the lone pair of the nitrogens. As highlighted by italic font in the figure, the most negative 


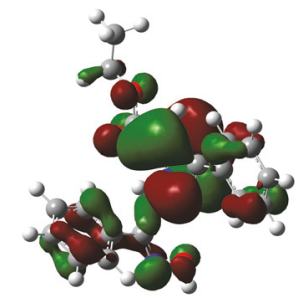

$\mathrm{HOMO}-4(-0.26884 \mathrm{eV})$

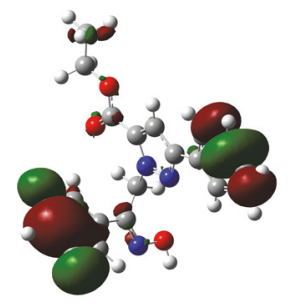

HOMO $-2(-0.25683 \mathrm{eV})$

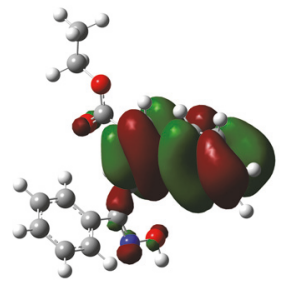

HOMO $(-0.22923 \mathrm{eV})$

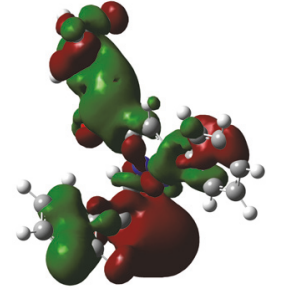

LUMO + $1(-0.04354 \mathrm{eV})$

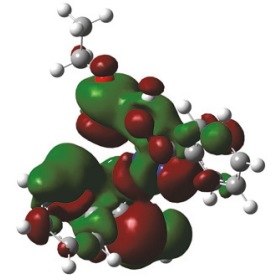

$\mathrm{LUMO}+3(-0.01384 \mathrm{eV})$

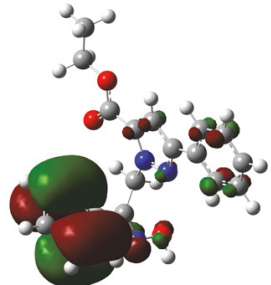

$\mathrm{HOMO}-3(-0.25915 \mathrm{eV})$

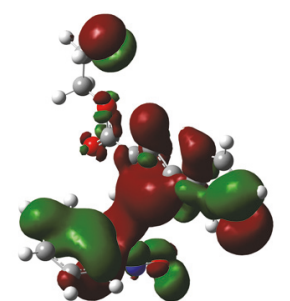

HOMO - $1(-0.24092 \mathrm{eV})$

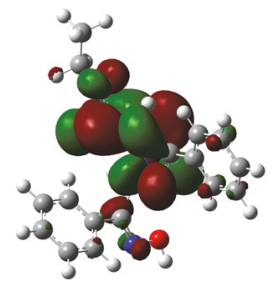

LUMO $(-0.05884 \mathrm{eV})$

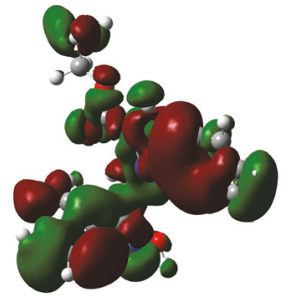

$\mathrm{LUMO}+2(-0.03342 \mathrm{eV})$

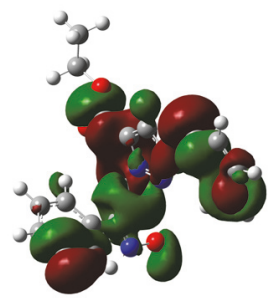

LUMO + $4(-0.01049 \mathrm{eV})$

FIGURE 6: Representative frontier molecular orbital plots of molecule.

point is the green sphere containing nitrogen atom in the five-membered ring, implying that it should be the most favorable site to form $\mathrm{H}$-bonds or interact with Lewis acids. Since this compound simultaneously possesses a strong $\mathrm{H}$ bond donor and various $\mathrm{H}$-bond acceptors, it is expected that the hydrogen bonds exist in its molecular crystal. Indeed, the actual crystal structure nicely validated this point. As shown in Figure 7(b), two pairs of equivalent hydrogen bonds can be clearly observed between two adjacent molecules in the crystal structure. Furthermore, we note that each of the hydrogen bonds can be approximately viewed as the result of fusion of global maximum and minimum of ESP, exhibiting that the formation of the hydrogen bonds completely follows the maximal electrostatic complementarity principle. The hydrogen bond length and bond angle are $2.82429 \AA$ and $170.793^{\circ}$, respectively, which are very consistent with the corresponding structural parameters of single crystal in Table 3. 


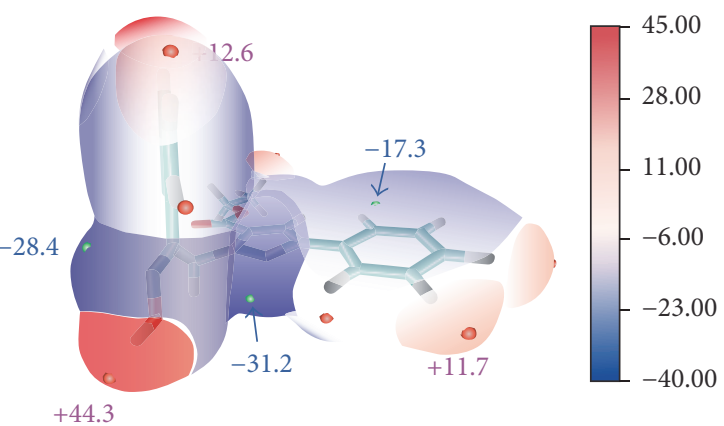

(a)

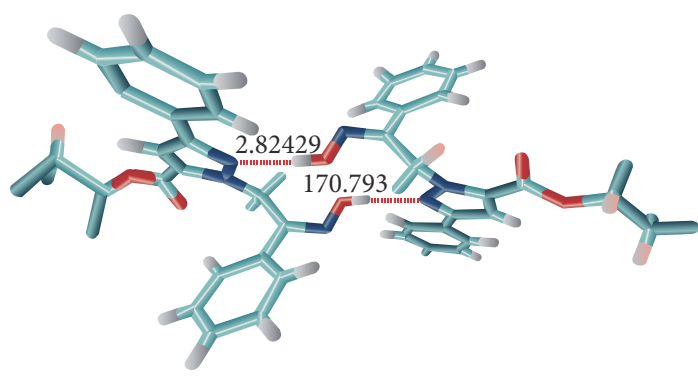

(b)

FIgURE 7: (a) ESP mapped molecular van der Waals surface of $Z$ isomer: the unit is in $\mathrm{kcal} / \mathrm{mol}$. Maxima of ESP and surface local minima are marked as orange and green spheres, respectively. The values of some prominent surface extremes are labeled on the graph, and the italic font labels global maximum and minimum. (b) An illustration of intermolecular $\mathrm{H}$-bond in the crystal of $\mathrm{Z}$ isomer: only a pair of dimers is shown for clarity, and the red-dashed lines correspond to the H-bonds.

\section{Conclusion}

In summary, ethyl 1-(2-(hydroxyimino)-2-phenylethyl)-3phenyl- $1 \mathrm{H}$-pyrazole-5-carboxylate is synthesized and featured by NMR, IR, MS, and X-ray single crystal diffraction. The geometries of $\mathrm{Z}$ and $\mathrm{E}$ isomers and the corresponding transition state (TS), as well as the dimer of $\mathrm{Z}$ isomer, are optimized using B3LYP hybrid functional coupled with def-TZVP triple-zeta polarized basis set. The bond angles and bond lengths of optimized structure of $\mathrm{Z}$ dimer are almost in full accord with crystal structural parameters. The combination of the weak intermolecular $\mathrm{C}-\mathrm{H} \cdots \mathrm{O}$ and $\mathrm{N}-$ $\mathrm{H}$... O hydrogen-bonding interactions stabilizes the crystal packing. The calculated hydrogen bond length and bond angle are $2.82429 \AA$ and $170.793^{\circ}$, respectively, which is very consistent with the corresponding structural parameters of single crystal. According to the crystal structure, the torsion angle of H1-O1-N1-Cl is $161(2)^{\circ}$, which reveals that the dominant configuration of double bond is $\mathrm{Z}$ configuration. Double-hybrid functional PWPB95-D3 in combination with very highly accurate basis set def2-QZVP is employed to evaluate the accurate energy of each isomer and TS. The calculated equilibrium constant between $\mathrm{Z}$ and $\mathrm{E}$ isomers is $4.29([\mathrm{Z}] /[\mathrm{E}])$, which is close to the value of 3.7 that is estimated according to the experimental NMR spectra.

\section{Conflicts of Interest}

The authors declare that there are no conflicts of interest regarding the publication of this work.

\section{Acknowledgments}

The theoretical calculations are performed in the laboratory of Professor Yuxiang Bu. In addition, the authors thank Professor Baoxiang Zhao very much for his helpful discussions. Their institution is School of Chemistry and Chemical Engineering, University of Shandong.

\section{References}

[1] H. Dai, J. Chen, H. Li et al., "Synthesis and bioactivities of novel pyrazole oxime derivatives containing a 5trifluoromethylpyridyl moiety," Molecules, vol. 21, no. 3, article no. 276, 2016.

[2] Y. Shi, S. Wang, H. He et al., "Synthesis and bioactivity of novel pyrazole oxime ester derivatives containing furan moiety," Chinese Journal of Organic Chemistry, vol. 35, no. 8, pp. 17851791, 2015.

[3] L.-W. Zheng, Y. Li, D. Ge et al., "Synthesis of novel oximecontaining pyrazole derivatives and discovery of regulators for apoptosis and autophagy in A549 lung cancer cells," Bioorganic \& Medicinal Chemistry Letters, vol. 20, no. 16, pp. 4766-4770, 2010.

[4] H. Dai, S. Ge, G. Li et al., "Synthesis and bioactivities of novel pyrazole oxime derivatives containing a 1,2,3-thiadiazole moiety", Bioorganic \& Medicinal Chemistry Letters, vol. 26, no. 18, pp. 4504-4507, 2016.

[5] H.-J. Park, K. Lee, S.-J. Park et al., "Identification of antitumor activity of pyrazole oxime ethers," Bioorganic \& Medicinal Chemistry Letters, vol. 15, no. 13, pp. 3307-3312, 2005.

[6] S.-L. Wang, Y.-J. Shi, H.-B. He, Y. Li, Y. Li, and H. Dai, "Synthesis and bioactivity of novel pyrazole oxime derivatives containing oxazole ring," Chinese Chemical Letters, vol. 26, no. 6, article no. 3284, pp. 672-674, 2015.

[7] G. Ouyang, X.-J. Cai, Z. Chen et al., "Synthesis and antiviral activities of pyrazole derivatives containing an oxime moiety," Journal of Agricultural and Food Chemistry, vol. 56, no. 21, pp. 10160-10167, 2008.

[8] G. Ouyang, Z. Chen, X.-J. Cai et al., "Synthesis and antiviral activity of novel pyrazole derivatives containing oxime esters group," Bioorganic and Medicinal Chemistry, vol. 16, no. 22, pp. 9699-9707, 2008.

[9] X. H. Liu, L. P. Zhi, B. A. Song, and H. L. Xu, "Synthesis, characterization and antibacterial activity of new 5-aryl pyrazole oxime ester derivatives," Chemical Research in Chinese Universities, vol. 24, no. 4, pp. 454-458, 2008.

[10] B. Sangepu, B. Gandu, G. Anupoju, and V. Jetti, "Synthesis of Isoxazole, 1, 2, 4-Oxadiazole and (1H-Pyrazol-4-yl)-methanone Oxime Derivatives from N-Hydroxy-1H-pyrazole-4-carbimidoyl Chloride and their Biological Activity," Journal of Heterocyclic Chemistry, vol. 53, no. 3, pp. 754-761, 2016.

[11] S. N. Shelke, C. H. Gill, M. S. More, S. B. Kale, S. M. Sonawane, and B. K. Karale, "Synthesis of novel benzo[d] oxazole derivatives as antimicrobial agents," Organic Chemistry: An Indian Journal, vol. 3, no. 1, pp. 40-44, 2007.

[12] R. R. Ranatunge, M. Augustyniak, U. K. Bandarage et al., "Synthesis and Selective Cyclooxygenase-2 Inhibitory Activity of 
a Series of Novel, Nitric Oxide Donor-Containing Pyrazoles," Journal of Medicinal Chemistry, vol. 47, no. 9, pp. 2180-2193, 2004.

[13] L.-W. Zheng, Z.-L. Gong, W.-L. Liu, Y.-R. Liu, and B.-X. Zhao, "Synthesis, X-ray crystal structure and fluorescent spectra of novel pyrazolo[1,5-a]pyrazin-4(5H)-one derivatives," Spectrochimica Acta Part A: Molecular and Biomolecular Spectroscopy, vol. 81, no. 1, pp. 372-379, 2011.

[14] D. S. Bolotin, M. V. Il'in, I. E. Kolesnikov et al., "Fluorescent (pyrazolyl acetoxime)ZnIIcomplexes: Synthetic, structural, and photophysical studies," Inorganica Chimica Acta, vol. 455, pp. 9-14, 2017.

[15] S. Viveka, G. Vasantha, Dinesha, S. Naveen, N. K. Lokanath, and G. K. Nagaraja, "Structural, spectral, and theoretical investigations of 5-methyl-1-phenyl-1H-pyrazole-4-carboxylic acid," Research on Chemical Intermediates, vol. 42, no. 5, pp. 44974511, 2016.

[16] A. Barakat, N. Shivalingegowda, N. Renuka et al., "Crystal structure of 3-(thiophen-2-yl)-5-(p-tolyl)-4,5-dihydro-1H-pyrazole1-carboxamide," Zeitschrift fur Kristallographie - New Crystal Structures, vol. 231, no. 1, pp. 267-269, 2016.

[17] O. V. Dolomanov, L. J. Bourhis, R. J. Gildea, J. A. K. Howard, and H. Puschmann, "OLEX2: a complete structure solution, refinement and analysis program," Journal of Applied Crystallography, vol. 42, no. 2, pp. 339-341, 2009.

[18] G. M. Sheldrick, "Crystal structure refinement with SHELXL," Acta Crystallographica Section C: Structural. Chemistry, vol. 71, pp. 3-8, 2015.

[19] P. J. Stephens, F. J. Devlin, C. F. Chabalowski, and M. J. Frisch, "Ab Initio calculation of vibrational absorption and circular dichroism spectra using density functional force fields," The Journal of Physical Chemistry C, vol. 98, no. 45, pp. 11623-11627, 1994.

[20] A. Schäfer, C. Huber, and R. Ahlrichs, "Fully optimized contracted Gaussian basis sets of triple zeta valence quality for atoms $\mathrm{Li}$ to Kr," The Journal of Chemical Physics, vol. 100, no. 8, pp. 5829-5835, 1994.

[21] M. J. Frisch, G. W. Trucks, H. B. Schlegel et al., Gaussian 03, Gaussian, Pittsburgh, PA, USA, 2003.

[22] L. Goerigk and S. Grimme, "Efficient and accurate doublehybrid-meta-GGA density functionals- evaluation with the extended GMTKN30 database for general main group thermochemistry, kinetics, and noncovalent interactions," Journal of Chemical Theory and Computation, vol. 7, no. 2, pp. 291-309, 2011.

[23] D. Rappoport and F. Furche, "Property-optimized Gaussian basis sets for molecular response calculations," The Journal of Chemical Physics, vol. 133, no. 13, Article ID 134105, 2010.

[24] F. Weigend, "A fully direct RI-HF algorithm: Implementation, optimised auxiliary basis sets, demonstration of accuracy and efficiency," Physical Chemistry Chemical Physics, vol. 4, no. 18, pp. 4285-4291, 2002.

[25] T. Lu and F. Chen, "Multiwfn: a multifunctional wavefunction analyzer," Journal of Computational Chemistry, vol. 33, no. 5, pp. 580-592, 2012.

[26] W. Humphrey, A. Dalke, and K. Schulten, "VMD: visual molecular dynamics," Journal of Molecular Graphics, vol. 14, no. 1, pp. 33-38, 1996.

[27] H. Becker and J. Fleming, "Frontier Orbitals and Organic Chemical Reactions," Journal Für Praktische Chemie, vol. 320, no. 5, pp. 879-880, 1978.
[28] J. S. Murray and P. Politzer, "Electrostatic Potentials: Chemical Applications," in Encyclopedia of Computational Chemistry, vol. 2, pp. 912-920, John Wiley and Sons, New York, USA, 1998.

[29] J. S. Murray and P. Politzer, "The electrostatic potential: an overview," Wiley Interdisciplinary Reviews: Computational Molecular Science, vol. 1, no. 2, pp. 153-163, 2011.

[30] P. Politzer and J. S. Murray, "Molecular Electrostatic Potentials and Chemical Reactivity," in In Reviews in Computational Chemistry, vol. 2, pp. 273-312, John Wiley and Sons, New York, USA, 1991. 

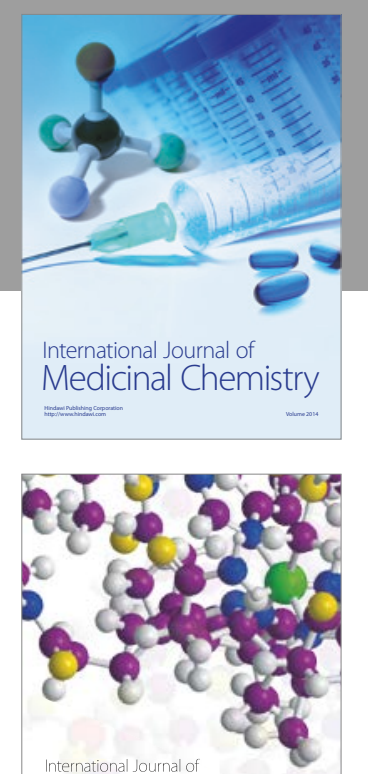

Carbohydrate Chemistry

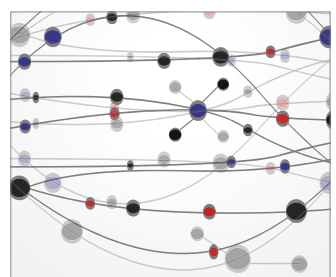

The Scientific World Journal
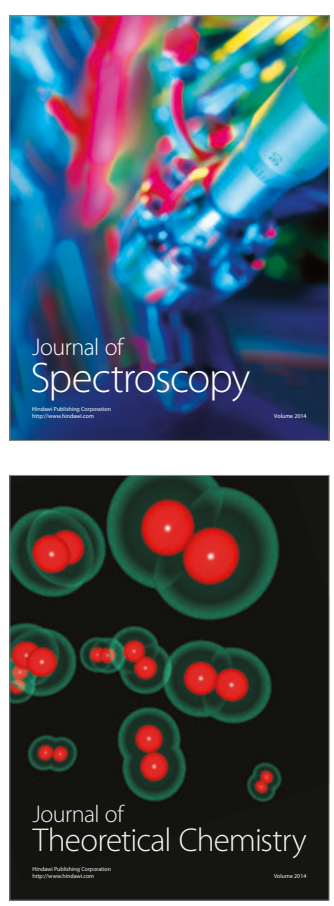
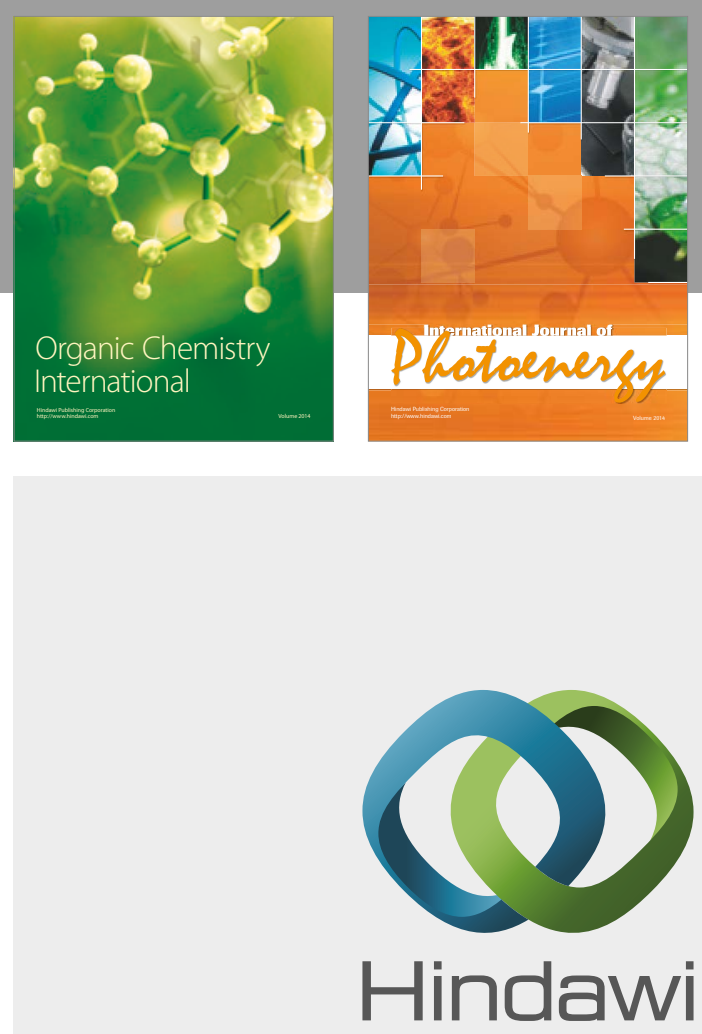

Submit your manuscripts at

https://www.hindawi.com

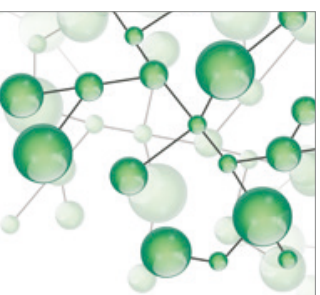

International Journal of

Inorganic Chemistry

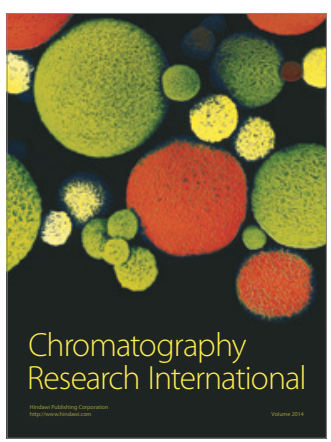

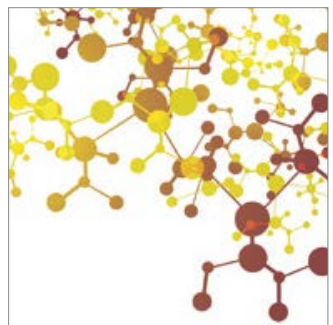

Applied Chemistry
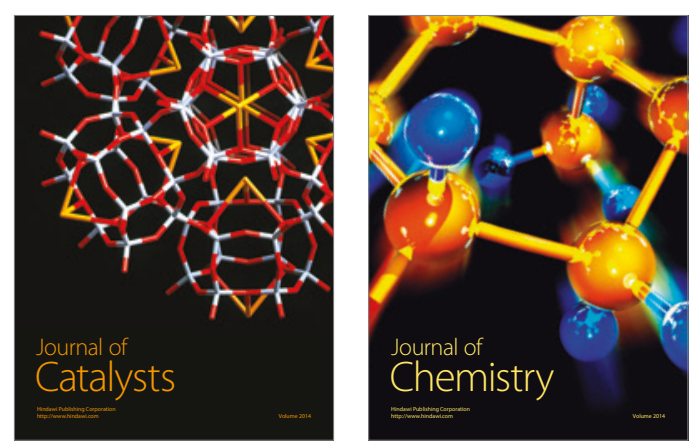
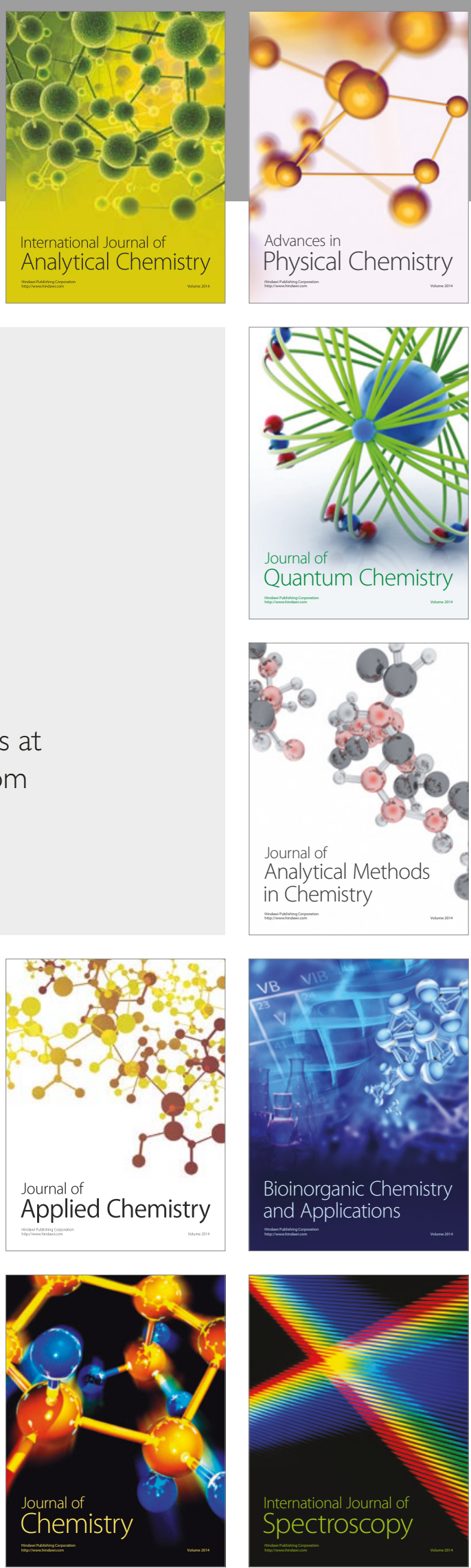